\title{
A psiquiatrização da vida: arranjos da loucura, hoje
}

The psychiatrization of life: arrangements of madness today La psiquiatrización de la vida: disposiciones de la locura de hoy

\section{Tania Mara Galli Fonseca}

Universidade Federal do Rio Grande do Sul, Porto Alegre, RS, Brasil.

\section{Regina Longaray Jaeger}

Universidade Federal do Rio Grande do Sul, Porto Alegre, RS, Brasil.

\section{Resumo}

A Política de Humanização da Atenção e da Gestão (PNH) tem como objetivo a qualificação das práticas de gestão e de atenção em saúde. O diferencial a que se propõe é a construção de plano transversalizando conceitos, funções, sensações, saberes, poderes, conectando produção de saúde ao campo da gestão. Plano que necessita ser permeado de novos sentidos para a saúde/adoecimento mental. A Reforma Psiquiátrica introduziu outros modos de tratar a doença mental, se mas percebe, mesmo assim, a naturalização e a perseveração dos diagnósticos e dos modos mais tradicionais de lidar com as condutas díspares. Neste sentido, devendo-se reafirmar que a PNH não se encontra orientada pela busca de prescrições, indagase: como o que se denomina saúde mental é tratada na rede HumanizaSus? O presente artigo propõe discutir a necessidade de uma formação que problematize os novos modos de gestão da vida, o controle normatizante das disparidades e os novos arranjos da loucura.

Palavras-chave: Loucura, Doença Mental, Poder psiquiátrico.

\footnotetext{
Abstract

The Humanization of health Care Policy and Management (PNH) aims qualification management practices and health care. The differential is that intends the construction plan transversal concepts, functions, feelings, knowledge, power, connecting to the production of health management field. It needs to be permeated with new meanings for health / mental illness. The Psychiatric Reform introduced other ways to treat mental illness but it is perceived, anyway, naturalization and perseveration of diagnoses and more traditional ways of dealing with diverse behaviors. In this direction, should be reaffirmed that the PNH is not
} 
oriented by the pursuit for prescriptions, asks: how what is called mental health is treated in the network HumanizaSUS? This article aims to discuss the need for training that problematizes the new ways of life management, control normalizing disparities and new arrangements of madness.

Keywords: Madness, Mental Disease, Psychiatric Power.

\section{Resumen}

La Política de humanización de la Atención y Gestión (PNH) tiene como objetivo la cualificación prácticas de gestión y de atención de la salud. El diferencial que propone es la construcción de planes transversalizando conceptos, funciones, los sensaciones, conocimientos, poderes conectando la producción de salud al campo de la gestión. Plan que hay que estar impregnado de nuevos sentidos para la salud / enfermedad mental. La Reforma Psiquiátrica presentó otras maneras de tratar la enfermedad mental, pero está claro, sin embargo, la naturalización y la perseverancia de los diagnósticos y las formas más tradicionales de hacer frente a comportamientos dispares. En este sentido, hay que reafirmar que la PNH no es impulsada por la búsqueda de prescripciones, se pregunta: ¿cómo lo que se denomina salud mental es tratada en la red HumanizaSUS? Este artículo tiene como objetivo discutir la necesidad de una formación que problematiza las nuevas formas de gestión de la vida, el controle normativo de las disparidades y las nuevas disposiciones de la locura. Palabras clave: la locura, la enfermedad mental, el poder psiquiátrico.

\section{Apresentação}

A luta pela democratização do país, no campo da saúde, se exprimiu em grande parte, pelo processo denominado Reforma Psiquiátrica, contemporâneo ao movimento sanitário, iniciado na década de 1970. Estes movimentos visavam à reformulação dos modelos de assistência e gestão, de defesa da saúde coletiva, equidade na oferta de serviços e tiveram como aspecto importante a participação dos trabalhadores e usuários de saúde nos processos de gestão e tecnologias de cuidado. Estes movimentos sociais heterogêneos conquistam direito nas instâncias máximas de decisões em saúde, confere ao SUS uma singularidade histórica e internacional de controle social. "Controle social, no sistema de saúde brasileiro, quer dizer direito e dever da sociedade de participar do debate e da decisão sobre a formulação, execução e avaliação da política nacional de saúde" 
(Ceccin, R.; Feuerwerker, 2004 p.43). Neste sentido, a Reforma Psiquiátrica referiu-se à ruptura da centralidade do procedimento psiquiátrico que separava e demarcava parte da população considerada doente mental e, portanto, incapaz de compartilhar sua vida no social. Para superar este modelo de gestão da população, a Reforma Psiquiátrica, com estreita relação com o movimento sanitário e à concepção de um SUS, empreendeu um conjunto complexo de transformações relacionadas à concepção de saúde e doença mental: "movimento que passa a reivindicar transformações das relações entre cultura e loucura, até então demarcadas pela normatização" (Lobosque, 2009, p.18).

O protagonismo dos usuários e dos trabalhadores compromissados na afirmação de um novo jeito de fazer saúde demarca a reorientação da nova ação política e institucional visando à superação do modelo de atenção a saúde mental centrado no manicômio. Neste sentido, a Política de Humanização da Atenção e da Gestão (PNH) contribui nesta nova configuração de forças instituintes com o objetivo de qualificação das práticas de gestão e de atenção em saúde. A humanização propõe-se a implementar condições de produção de novas atitudes por parte dos trabalhadores, gestores e usuários, de novas éticas no campo da gestão do trabalho e das práticas de saúde. Isto implica em práticas sociais ampliadoras dos vínculos de solidariedade e co-responsabilidade, através da tríplice inclusão: nos espaços da gestão, do cuidado e da formação, de sujeitos e dos coletivos (Passos \& Pasche, 2010, p.7). Deste modo, os princípios de $\mathrm{PNH}$ afirmam a inseparabilidade entre gestão e cuidado, a transversalidade das práticas ampliadoras da comunicação e dos processos de negociação "permitindo a criação de zonas de comunalidade e projetos comuns" (Pasche \& Passos, 2010, p. 7). A Política de Humanização pode ser entendida como a construção de um plano de ação cujas práticas tecem redes transversalizando conceitos, funções, sensações, saberes, poderes, conectando produção de saúde ao campo da gestão. A PNH não busca prescrever um "modo certo de se fazer" por considerar tais atos relacionados a uma discursividade moral e normatizante. Busca afirmar uma política ampliadora de responsabilidades, singularidades e gestão produtora de saúde:

\footnotetext{
A inclusão tem o propósito de produzir novos sujeitos capazes de ampliar suas redes de comunicação, alterando as fronteiras dos saberes e dos territórios de poder; e de conectar suas práticas de produção de saúde ao campo da gestão,
} 
pois aquelas derivam das condições institucionais que definem os modos de funcionamento da organização, tarefa da gestão. (Passos \& Pasche, 2010, p.7).

Para a PNH, diretrizes éticas e políticas do cuidado e da gestão se concretizam no acolhimento, na clínica ampliada, na democracia das relações, na valorização do trabalhador, na garantia dos direitos dos usuários e no fomento de redes. Mas para quem são orientados estes cuidados? Quais são os usuários a quem direcionamos os cuidados de atenção e gestão humanizada? Quais são as condições e circunstâncias que determinam ao usuário os lugares que passa a ocupar nas diferentes redes que constituem a atenção à saúde? Como as políticas públicas acompanham as necessidades da população?

O movimento da Reforma Psiquiátrica ao romper com a centralidade do manicômio se propôs a produzir novos conceitos, novas funções e novas percepções da loucura. Trata-se de rupturas que fazem parte da formação e da concepção do SUS na medida em que propõe um conjunto de transformações relacionadas aos modos de cuidar da saúde humana. Apesar das intenções reformistas, que propunham a superação das internações, de sua substituição através de serviços de assistência, das transformações de nossos modos de cuidar da saúde, percebe-se uma naturalização dos diagnósticos e persistência dos modos mais tradicionais como temos nos referido a esta característica humana, denominada Transtorno Mental. A loucura, o díspar, tende a ser incorporado na vida comum, na versão de doença mental psiquiátrica. Subjetivados como doentes mentais a partir de condições pré-determinadas pelas classificações psiquiátricas, os indivíduos submetem-se ou são submetidos a viver dependentes de instituições de cuidados.

Por esta via, assistimos, no contemporâneo, a uma progressão epidêmica de doenças psiquiátricas que não podemos ignorar. Segundo a Organização Mundial da Saúde, estima-se que os transtornos depressivos unipolares estão em terceiro lugar na classificação da carga global de adoecimentos. Além do que, governos estão especialmente preocupados com as perdas econômicas relacionadas a estas doenças (Lancet, 2012, p.1203). No Brasil, o número de acidentes de trabalho no Brasil apresentou uma redução de ocorrências, enquanto os transtornos mentais e comportamentais passaram a ocupar o terceiro lugar em quantidade de concessões de auxíliodoença. Dentre os transtornos mentais e comportamentais que mais afastaram os 
trabalhadores em 2011 foram Episódios Depressivos, Outros Transtornos Ansiosos e Reações ao Estresse Grave e Transtornos de Adaptação (MPS, 2012).

Como então a PNH vem tratando das configurações relacionadas à loucura? A política nacional de humanização tem o grande desafio de construção de um SUS orientado para o protagonismo, autonomia e co-responsabilidade de todos os atores envolvidos. Formação que envolve a construção de novas práticas de saúde e que seja capaz de acionar novos modos de ser, de sentir, de agir intervindo nos modos de gestão de saúde, capazes de produzir "novos sujeitos", ou seja, co-responsáveis e partícipes na afirmação das políticas do SUS. Como acolhemos os díspares em instituições de saúde? Como acolher usuários e trabalhadores em situações de sofrimento mental, físico, moral, sem naturalmente selecioná-los, classifica-los e generaliza-los a determinadas categorias de doenças?

Seremos capazes de propor novas práticas políticas quando estamos imersos em um mundo onde instrumentos panópticos generalizados arregimentam cada vez mais novas materialidades, onde a vigilância absolutamente faz parte desta trama mais comum de nossas vidas?

Quais são as escolhas que determinam as necessidades de cuidados destinados à população? Quais são os critérios avaliativos sobre os corpos que determinam as orientações dos mecanismos institucionais de atendimento? Quais as condições de entrada e saída do usuário na rede de atenção à saúde?

Propomos examinar possibilidades de viver sem assujeitar o pensamento a comparativos relacionados ao "jeito bom de ser"; Fazer um esforço para romper com nossos binarismos e nossos critérios de corte; viver a vida a partir da diferença, dos processos transversais que constituem os arranjos heterogêneos que constituem nossas existências.

São inequívocos os avanços da Reforma Psiquiátrica, da ampliação e complexificação dos cuidados relativos aos usuários, da reorganização institucional dos atendimentos com o objetivo da inclusão protagonista dos diferentes segmentos sociais envolvidos na saúde. Conquistas políticas, ainda em francas disputas com regimes concentrados em modelos biomédicos, perseveraram. Em nome da prevenção, dos riscos, dos estados potenciais de adoecimento, do crescente aumento de distúrbios mentais somos tentados a reforçar políticas relacionadas às classificações diagnósticas, relacionando condutas a estados de anormalidades que não podem ser corrigidas. Propomos pensar sobre o processo e ampliação de 
saberes, de poderes na atenção a saúde e as medidas escolhidas pelo Estado para melhorar a vida das pessoas. Abrir linhas que transversalizam o campo unitário do discurso psiquiátrico através da arqueologia foucaultiana como uma prática para romper com as dicotomias ainda tão demarcadas em nossas práticas. Em suma, acontecimentalizar a evidência de nossas práticas e dos saberes constituídos pelo arquivo da loucura.

Chamarei arquivo não a totalidade de textos que foram conservados por uma civilização, nem o conjunto dos traços que puderam ser salvos de seu desastre, mas o jogo das regras que, numa cultura, determinam o aparecimento e o desaparecimento dos enunciados, sua permanência e seu apagamento, sua existência paradoxal de acontecimentos $e$ de coisas. Analisar os fatos de discurso nos elementos gerais do arquivo é considerá-los não absolutamente como documentos (de uma significação escondida ou de uma regra de construção), mas como monumentos; éfora de qualquer metáfora geológica, sem nenhum assinalamento de origem, sem o menor gesto na direção do começo de uma arché-fazer o que poderíamos chamar, conforme os direitos lúdicos da etimologia, alguma coisa como uma arqueologia (Foucault, 2004, p.95).

$\mathrm{O}$ arquivo da loucura, o jogo de regras que seleciona, dentro da massa de discursos efetivamente falados sobre a loucura, os que permanecem com suas regras, práticas de funcionamento; o que pode ser dito, conservado e reativado na memória. É preciso fazer a acontecimentalização dos saberes, constituídos por esta arqueologia, ou melhor, por uma genealogia ou uma cartografia:

$$
\begin{aligned}
& \text { Que é preciso entender por } \\
& \text { acontecimentalização? Uma ruptura da } \\
& \text { evidência, primeiramente. Aí, onde se } \\
& \text { estaria bastante tentado a se referir a uma } \\
& \text { constante histórica ou a um traço } \\
& \text { antropológico imediato ou ainda a uma } \\
& \text { evidência se impondo do mesmo jeito a } \\
& \text { todos, trata-se de fazer surgir uma } \\
& \text { 'singularidade'. (...) Analisar os } \\
& \text { acontecimentos que a história } \\
& \text { "desacontecimentalizou” } \\
& \text { mecanismos em } \\
& \text { antropomórficos (Foucault,1994, p.23- } \\
& \text { 25). }
\end{aligned}
$$

A questão que Foucault coloca é analisar os acontecimentos com a tarefa de discerni-los, dentro dos agenciamentos, "achar de novo as conexões, os encontros, os apoios, os bloqueios, os jogos de força, as estratégias..." (Foucault, 1994, p.23). Recusar, portanto, as análises que se referem a um campo simbólico, da língua e dos signos: 
A historicidade que nos leva e nos determina é belicosa; ela não é linguageira. Relação de poder, não de sentido. A história não tem sentido (...) ao contrário, ela deve poder ser analisada até dentro de seu menor detalhe: mas segundo a inteligibilidade das lutas, das estratégias e das táticas. (Foucault, 1994 p.145)

\section{Remarcados caminhos}

A partir de Michel Foucault, Gilles Deleuze e Félix Guattari, traçamos novos planos de imanência, de referência e de composição para analisar os campos de saberes da saúde, que nos convidam a novas apreensões do mundo. Enfatizamos estes autores apenas por medidas de precaução. São autores que concebem arranjos coletivos e maquínicos que rompem com formações discursivas subjetivantes, organizadas em torno do conceito de sujeito (humano, falante, trabalhador, consumidor). E, cada vez que pensamos que os alcançamos, eles escapam. Repetição da diferença, sempre há algo novo nestes encontros. Jogo tenso e lúdico dos saberes sempre recomeçados. Jogos inconformes com o que aí se apresenta. Jogos de saber que induzem ao comentário, ao abandono de ferramentas conceituais por cansaço e/ou enfado. Insistiremos mais um pouco, quando ainda resta fôlego ou mesmo por teimosia. Mas também por sentir que ainda oferecem matérias e acontecimentos inesgotáveis.

Foucault nos fornece elementos importantes que permitem questionar $o$ modo como o sofrimento mental, físico, social, econômico vem ganhando cada vez mais o estatuto de doença mental e se afirma cada vez mais em novos arranjos em nossa existência mais comum. E com isto, o poder psiquiátrico vai adquirindo cada vez mais novos poderes em função da proteção, vigilância e segurança estatais contra os desvios sociais.

O processo de produção do devir humano foi atravessado pela psiquiatrização que se dá concomitante à formação dos Estados modernos, ao processo de urbanização, ao processo de trabalho remunerado, ao processo de asilamento dos considerados incapazes. Psiquiatrizando-se, o devir-humano do animal se prende a equipamentos, matérias que dão corpo a uma produção "conceitual-filosófica, funcional-científica e perceptiva/afetiva-artística" (Deleuze \& Guattari, 1992). Assim, se criam conceitos filosóficos, inventam-se personagens conceituais pró-filosóficos e traçam-se um plano de imanência pré-filosófico (Deleuze \& Guattari, 1992, p.57, p.76). Do mesmo esforço, surgem funções científicas, observadores parciais e um plano de 
referência, bem como, eclodem perceptos e afetos, situações estéticas e um plano de composição. E assim, justificam-se os agenciamentos que constituem doenças.

Na modernidade, o homem da razão delega ao médico a relação com a universalidade abstrata da doença do louco. E este, por sua vez, comunicar-se-á com o médico através da intermediação de uma razão abstrata, "que é ordem, coação física e moral, pressão anônima do grupo, exigência de conformidade" (Foucault, 1999, p.141). "A linguagem da psiquiatria, que é o monólogo da razão sobre a loucura, só pode estabelecer-se sobre um tal silêncio" (Foucault, 1999, p.141). Silenciamento que vem antes da constituição da loucura como doença mental. Vem do gesto primitivo de recusa da experiência-limite que cria a possibilidade de história. A história impõe o silenciamento de certos acontecimentos. É aí que é possível a separação, muito antes, portanto, da própria psiquiatrização da loucura: é "a percepção que o homem ocidental tem de seu tempo e de seu espaço que deixa aparecer uma estrutura de recusa, a partir da qual denunciamos uma fala como não sendo linguagem, um gesto como não sendo obra, uma figura como não tendo direito a tomar lugar na história" (Foucault, 1999, p.144). A condição da história a partir do século XVIII exige a existência da loucura, do não-sentido ou da reciprocidade loucura e não-loucura.

Até pouco tempo, o poder psiquiátrico parecia ter um domínio próprio, território pronto onde era permitido dizer quem era louco e nãolouco. O campo da saúde mental vai desterritorializar este domínio e reterritorializá-lo, de modo ampliado, a novos domínios da prevenção, da promoção, da reportação à doença mental em nome de uma saúde mental. Os procedimentos psiquiátricos passam a fazer parte de vários domínios do conhecimento: da educação, da justiça, do trabalho... "Parece-me que esta difusão do poder psiquiátrico realizou-se a partir da infância, isto é, a partir da psiquiatrização da infância" (Foucault, 2006, p. 255). Até meados do século XIX, o desenvolvimento mental infantil era selecionado, dentro de uma elaboração teórica que sustentava a possibilidade de "correção": "idiotias" e "atrasos" mentais eram passíveis de serem curados. Ao longo do século XIX, "é do lado dos pares hospital-escola, instituição sanitária (instituição pedagógica, modelo de saúde)- sistema de aprendizagem que se deve buscar o princípio de difusão desse poder psiquiátrico (Foucault, 2006, p. 255256). A psiquiatria rompe com seus limites relacionados à doença mental, tratamento e cura, buscando, no desenvolvimento 
infantil, amostras e evidências de que há um estado anormal que deve ser devidamente demarcado. A incorporação da criança pelo poder psiquiátrico não passou pela criança louca ou pela loucura da infância. A psiquiatrização da infância foi encarnada pela criança que não acompanha o desenvolvimento normatizado, aquela que, ao não acompanhar as tarefas da escola, logo será chamada atrasada. De modo que, a generalização do poder psiquiátrico vai se fazer a partir de dois processos. O primeiro, através da elaboração teórica do que é idiotia, noção distinta da doença mental. Serão determinadas as condições que vão indicar atraso e/ou ausência do desenvolvimento, a lentidão e o bloqueio. Estas noções teóricas estabelecem um padrão temporal do desenvolvimento humano, onde estão repartidas as organizações neurológicas e psicológicas, funções, comportamentos e aquisições. Ao adulto caberá a norma como ponto terminal e ideal do desenvolvimento e à criança, caberá a norma de velocidade do desenvolvimento. Processo comum a todos humanos, balizado por um ponto ótimo de chegada: "o desenvolvimento é portanto uma espécie de norma em relação à qual nos situamos, muito mais do que uma virtualidade que possuiríamos em nós" (Foucault, 2006, p. 263). De modo que o processo de expansão da psiquiatria vai acontecer através da incorporação de variações de uma temporalidade de desenvolvimento normativo, não definidas ainda, como doenças mentais.

Por outra via, o fenômeno das práticas de anexação institucional da anomalia aos espaços da psiquiatria ocorre a partir da necessidade do modelo capitalista de trabalho. "A assimilação institucional 'idiota e louco' se faz a partir da necessidade de liberar os pais para o trabalho" (Foucault, 2006, p.271). A internação destas "crianças-obstáculos" será plenamente justificada. $\mathrm{O}$ conceito de alienação mental rompe com as diferentes categorias, amplia as necessidades de internar tudo o que fosse considerado díspar ao desenvolvimento normal. É esta criança não-louca que, no início do século XIX, passa a ser objeto de cuidados: a criança atrasada não é uma criança doente, mas uma criança anormal. Sobre esta criança confiscada será exercido o mais puro poder psiquiátrico. "E que é que faz o tratamento psiquiátrico dos idiotas, senão, precisamente, repetir sob forma multiplicada e disciplinar o conteúdo da educação?"(Foucault, 2006, p. 276). É deste entrelaçamento de novas ramificações que a psiquiatria vai se disseminar pelos regimes disciplinares, detectando defasagens nos mais diferentes 
campos: escolar, militar, familiar, laboral. Por reportação ao poder disciplinar que determina um modo certo de ser, em qualquer área da vida, qualquer desvio será considerado anomalia para a psiquiatria. Por esta via, generalizações disseminam o poder psiquiátrico, ampliando o espectro do doente mental para toda e qualquer comportamento considerado anormal. Esta expansão do poder psiquiátrico acoplado ao poder da educação alia-se, contemporaneamente, ao mercado de trabalho. Refere-se a um território fortemente demarcado por esquadrinhamentos disciplinares dos comportamentos, que criam novas realidades de adoecimento fundados nestes poderes.

A psiquiatria terá um novo alcance, alarga seus espaços de atribuições e funções. Todos os comportamentos adultos passam a ser comparados com o estatuto fixo do desenvolvimento normal da infância. Não se trata apenas de confiscar a criança com desenvolvimento incomum. Trata-se de passar a psiquiatrizar as condutas, de crianças e adultos, que podem ser comparadas às condutas infantis. Reforça o caráter de fixidez a partir de um balizamento do que é considerado normal e esperado. Este princípio produtor e regulador das condutas, não é mais uma doença "mas um certo estado que vai ser caracterizado como estado de desequilíbrio, isto é, um estado no qual os elementos vêm funcionar num modo que, sem ser patológico, sem ser portador de morbidez, nem por isso é um modo normal" (Foucault, 2001, p. 391). A amplitude do espectro da loucura referenda um funcionamento social esperado. Eis, portanto, uma das funções do poder psiquiátrico: controle social. O processo de transformação da psiquiatria em tecnologia de defesa, proteção e ordem social se dá através da generalização do processo psiquiátrico e alargamento de seu campo de incidência a partir do processo de psiquiatrização da infância.

Da mesma forma, ao utilizarmos palavras como controle social, sofrimento psíquico, humanização dos tratamentos, incapacidade laboral, saúde mental, desestigmatização da doença de forma generalizada, corremos o risco de nos inscrevermos cada vez mais no maquinismo da ordem estatal dos poderes intercalados de soberania, de normalização disciplinar e segurança, e de controle. Através de uma rede de cuidados estatais, somos capazes de alcançar os mais íntimos espaços para dominar, controlar, decidir questões sobre a vida das pessoas.

Se, em um primeiro momento, a psiquiatria preocupou-se em assegurar seu saber sobre parte da população demarcada 
como doente mental, incapaz de convívio social, a partir da metade do século XIX, passa a circunscrever todas as condutas consideradas desviantes. Morel ao introduzir a noção de "estado" nos anos 1860-70 amplia o campo das anormalidades do qual pode advir qualquer doença, a qualquer momento. Refere "à não-saúde mas que pode, ao mesmo tempo, acolher em seu campo qualquer conduta a partir do momento em que ela é fisiológica, psicológica, sociológica, moral e até juridicamente desviante" (Foucault, 2001, p. 398). Mais um elemento integrase às razões das anormalidades da população. O indivíduo portador de um estado de disfuncionamento carrega consigo uma carga biológica. As demarcações se estendem pelos corpos familiares. Sempre haverá algum estado de anormalidade que justifique ou predisponha ao estado de adoecimento, as degenerações. Mantém-se a medicina do patológico e da doença e inclui-se a medicalização do anormal, incurável e perigoso. A partir da medicalização ou gestão das condutas anormais generalizadas, a psiquiatria formula a teoria da degeneração: o degenerado "é a peça teórica maior da medicalização do anormal". É quando o portador de qualquer desvio será reportado a um estado de degeneração: "vê-se que ela (psiquiatria)

passa a ter uma possibilidade de ingerência indefinida nos comportamentos humanos" (Foucault, 2001, p.401).

Ao se dar o direito de desconsiderar a doença e relacionar o estado de anormalidade a uma degeneração, a psiquiatria não mais se atribui a exigência de curar. Efetua simplesmente a função de proteção e de ordem contra os degenerados: "ela se torna a ciência da proteção científica da sociedade, ela se torna a ciência da proteção biológica da espécie" (Foucault, 2001, p. 402). Em nome da defesa e garantia de proteção da sociedade, ela pretende "ser a instância geral de defesa da sociedade contra os perigos que minam do interior" (Foucault, 2001, p. 403). Todo um maquinismo reforça a tautologia psiquiátrica estendida à psicologia, ao serviço social, ao serviço educacional: circunscrever comportamentos anormais, fixar em classificações, gerenciar para que sejam controlados. Em nome da proteção, toda e qualquer referência de anormalidade será circunscrita ao âmbito da medicalização. A psiquiatria (a educação, o trabalho, o lazer...) assume a função de defesa da sociedade contra seus perigos.

\section{$O$ gesto incessantemente repetido}


Desordens neurológicas, desordens econômicas, desordens sociais. A vida produz sofrimentos que, a qualquer sinal, tendem a receber alguma categoria. E é deste ponto que a psiquiatria, a psicologia, o serviço social, amplificam seu poder na gestão de nossas vidas. A população psiquiátrica, com a Reforma Psiquiátrica não perdeu este nome. Cada vez mais, descobre-se novos doentes nas fábricas, nas escolas, nos hospitais gerais. Incessantemente recolhemos estas demandas, exercemos nossa razão científica, estabelecemos as devidas marcas institucionalizantes que potencializam novas produções maquínicas. Quando pensávamos em diminuir os loucos do hospício, constituíamos, através dos procedimentos desterritorializados da ciência psiquiátrica e psicológica, novos objetos doentes. A indústria, o Estado, a comunicação, a arte entram neste festim. Para reabilitar, curar, integrar, a loucura tornou-se um grande negócio. Novos procedimentos, novos espaços, novas linguagens constatam a divisão já estabelecida. Resta algo indiferenciado? Neste texto, buscamos nos aproximar desta maquinaria expressiva, analisando alguns de seus arranjos, seus movimentos territorializantes e desterritorializantes. Procuraremos abrir as palavras-atos e os corpos que constituem estes arranjos.

A condição da psiquiatria é da patologização permanente. Procedimento psiquiátrico que sai dos territórios bem demarcados dos manicômios e se alonga através de mecanismos heterogêneos, cada vez mais fortes, mais ampliados, mais estendidos, intervindo na vida mais comum. Em nome da segurança e da proteção social, a psiquiatria toma para si, o poder sobre a vida, determinando, o direito soberano de vida e de morte: se não se tratar, se não seguir a prescrição exata, se não tomar a medicação... morrerá...

Mas qual é a experiência da loucura na atualidade? De quais matérias e acontecimentos é constituída? A loucura, na sua versão doença mental, desamarra-se das camisas de força dos hospitais psiquiátricos para novos dispositivos terapêuticos. Procedimentos manicomiais de tratamento e cura ampliam-se em inúmeros serviços públicos. No ambiente privado, reservam-se o direito ao sigilo silencioso. No ambiente público, restam os direitos sociais adquiridos. Este conhecimento racional que denominamos doença mental, este acidente patológico, ao qual foi reduzida a loucura, está ligado ao gesto de decisão, "que destaca do ruído de fundo e de sua monotonia contínua uma linguagem significativa, que se transmite e 
conclui no tempo: em suma, ela está ligada à possibilidade da história" (Foucault, 1999, p. 145).

$\mathrm{Na}$ experiência da loucura, da segregação e da exclusão (e inclusão em outro lugar) (Foucault, 1999, p. 149), dentro das normas de sensibilidade que a isolam e capturam, as dores e as palavras do louco não existem senão pelo gesto de divisão que as denuncia e as domina. "É somente no ato de separação e a partir dele que se pode pensá-las como poeira ainda não separada" (Foucault, 1999, p. 146). Ato de decisão, que liga e separa razão e loucura, o que faz oposição entre o sentido e o insensato. Trata-se de um discurso indireto livre, murmúrio anônimo, glossolalia que expressa os acontecimentos que se encarnam num agenciamento maquínico, em que o ato da palavra, pode expressar as dicotomias razão-loucura.

Caberia ao trabalho a consideração de grande produtor de sofrimentos submetidos a categorias de adoecimento?

Diz uma trabalhadora, ouvida pelo serviço de atendimento de um hospital público na França ${ }^{1}$ :

...estou na linha de produção desde os 17 anos. Sinto-me como uma máquina. Cada vez mais rápida, ninguém me acompanha. Onde havia 3 agora há 1.Quanto mais rápido, mais reduzem o pessoal. Temos que ser competentes, se não conseguimos acompanhar perguntam: você não é mais competente? Ficamos completamente humilhados.

A função de sua fala para o terapeuta é mostrar o que resta, a dor, a queixa, o sofrimento. Parte do agenciamento da empresa e do mundo, ele pouco ou nada pode fazer. A "peça trabalhador" recebe uma escuta acurada, sensível expondo sua função produtora reduzida e silenciada em uma organização. No atendimento consegue falar de sua experiência de "enlouquecer" a partir de mecanismos outros, arranjos heterogêneos que não são remetidos imediatamente ao mental.

Maquinismo eficiente, ativado por discursos de competitividade, pode produzir efetivamente múltiplos acontecimentos desconsiderados, invisibilizados, que não ganham relevância. Maquinismo que produz renda, conhecimento, trabalhadores-resistentes, trabalhadores-doentes...

Fazemos parte de uma grande máquina capitalista movida por atos que separam comportamentos adequados e não adequados ao capital. Financiamentos estatais ampliam empreendimentos, produzem mais dinheiro, competitividades, e cada vez mais doentes. 


\section{Desconstituindo discursos, amplificando sutis acontecimentos}

Apesar de contribuições acadêmicas vastíssimas, por que contribuímos com tão pouco nos modos como lidamos com a diferença, permanecendo, por exemplo, no campo jurídico dos direitos em relação à saúde mental? Como bons guardiões estatais, insistimos em garantir direitos às necessidades da população. E quem precisa de quê? O Estado entra para conceder aquilo que falta. Falta sustentada por aquilo que é considerado a partir do desvio, das incapacidades biológicas diversas, dos efeitos do meio e sobre tudo o que "a biopolítica vai extrair seu saber e definir o campo de intervenção de seu poder" (Foucault, 2010, p.206). Mas o que é que falta para potencializar de modo alegre nossas vidas?

Estranhezas e incertezas do mundo, meros acontecimentos, enclausurados pelas verdades aportadas nas fronteiras entre a razão e a desrazão. Destacamos, depuramos, hierarquizamos, ordenamos modos de ser, pensar e sentir em nome de verdades. Criamos espaços reais, efetivos, desenhados na própria instituição da sociedade, espécies de utopias realizadas. São entrecruzamentos de linhas mesmo incompatíveis, abertas, fechadas, substituíveis. Trata-se de heterotopias que, nos termos de Foucault, correspondem a criação de lugares cujas finalidades específicas é a normalização da sociedade. São espaços "singulares", "reais", "localizáveis" que se encontram dentro de certos espaços sociais, cujas funções podem se opor ao próprio funcionamento social. Admitidos dentro de sua base social, "própria de todos os grupos sociais e de todas as culturas" criadas para além dos próprios recortes criados pela sociedade. Lugares outros, "espécie de contestação, simultaneamente mítica e real, do espaço em que nós vivemos" (Foucault, 1994, p. 755-756). Constituímos espaços estatais comuns reservados para os cuidados à saúde, e, por sua vez, construímos espaços outros reservados para o exercício do cuidado em saúde mental de uma determinada população diferenciada. A constituição de um espaço específico para atendimento de saúde mental pode, neste sentido, ser entendido como Heterotopias de desvio: "são aquelas nas quais os indivíduos, cujos comportamentos são desviantes em relação à norma ou média necessárias, são colocados" (Foucault, 1994, p.757). Não são espaços comuns de cuidados com a saúde, são espaços específicos, reais, efetivos desenhados para uma população "necessitada" de cuidados em saúde 
mental. Se antes dos movimentos reformistas, o atendimento era reservado aos desviantes "irrecuperáveis" das heterotopias do desvio, como os hospitais psiquiátricos, agora toda a população pode ter suas necessidades atendidas através das novas instituições de saúde mental. Qualquer desvio da norma comportamental pode ser considerado caso de saúde mental que deve ser acolhido pela heterotopia do desvio. Apoiada em uma base institucional, diz Foucault, toda uma espessura de práticas é constrangida ao poder centralizador, ligadas à instituição e ao funcionamento de um discurso científico organizado no interior de uma sociedade como a nossa (Foucault, 2005, p. 171).

Em nome das verdades, a produção discursiva exorciza poderes e perigos dos acontecimentos, mas encarnam-se outros acontecimentos.

Estamos reduzindo nossas trajetórias desterritorializantes às heterotopias disciplinadoras e controladoras ao ampliado do discurso psiquiátrico? Na tentativa de saída dos procedimentos de desmanicomialização, destacamos duas trajetórias desterritorializantes dos procedimentos psiquiátricos abertas pelas instituições estatais. A desterritorialização dos velhos procedimentos de atenção dos espaços confinados e a reterritorialização destes antigos procedimentos em heterotopias especializadas do desvio, ainda destinadas a cura e a reabilitação. E a desterritorialização dos procedimentos psiquiátricos e a sua renovação, a busca da construção de relações com a saúde, com o singular, com a diferença. Estamos conseguindo construir novas relações com a saúde, romper com as heterotopias do desvio estigmatizante?

Ampliamos os serviços de atendimento à saúde mental, buscamos articular políticas públicas em uma rede, realizamos uma clínica ampliada, lutamos por uma gestão do SUS humanizada, integrada e solidária. Ao tentar retirar da loucura o estigma da doença mental, dos modelos biomédicos, sintomatológicos e eminentemente terapêuticos, ao propor uma ampliação integral de cuidados para o indivíduo em sua totalidade, busca-se romper com o território fechado da doença mental. Todavia, utilizando conceitos como saúde mental, sofrimento mental, corremos o risco de generalizações e amplificação do próprio espectro da anormalidade, do que não vai bem, do que precisa necessariamente do cuidado do Estado. Ampliamos o objeto de saúde mental para todos. Se a passagem pelos serviços de saúde mental demarcavam determinados usuários considerados 
doentes mentais, agora a demarcação se amplia. O padrão se torna mais avaliativo. Toda e qualquer conduta de forma geral pode passar a ser visibilizada e sentida como anormalidade. Dores de cabeça, dores musculares, passam a ser englobadas numa ampla categoria de sofrimento mental. Todos somos suscetíveis de sermos marcados em qualquer esfera da vida, através do gesto que avalia, classifica e separa segundo o padrão social esperado.

A psiquiatria alongada no social passa a ser incorporada através de arranjos heterogêneos e multifacetados. O usuário que passa a fazer parte de uma rede humanizada de saúde, ao exercer seus direitos de cidadania, recebe a dupla inscrição, conforme nos indica Agambem. De um lado, os direitos adquiridos de acesso à saúde finalmente adquiridos a partir de lutas e rupturas com os poderes estatais, de outro prepararam, "uma tácita, porém crescente inscrição de suas vidas na ordem estatal, oferecendo assim uma nova e mais temível instância ao poder soberano do qual desejaria libertar-se" (Agamben, 2002, p.127).

Em defesa da população, fazemos determinadas escolhas em detrimento de outras, e isto está relacionado a uma ideia de riscos que os movimentos de humanização e desestigmação podem incorrer ao tratarem da saúde mental. Se o movimento da reforma psiquiátrica rompeu o processo de totalização dos espaços asilares, esta saída possibilitou a agregação de novos arranjos da loucura, mais humanizada, menos estigmatizada. Em prol de um atendimento necessário, construímos totalidades, um "lugar melhor", ampliamos espaços para atendimento da loucura. Apesar de nossas intenções de promover saúde e autonomia, tais usuários muitas vezes permanecem convencidos de que nenhum outro lugar será melhor do que o serviço substitutivo. Destitui-se e é destituído dos lugares sociais por suas diferenças, classificadas em anormalidades. Desvios normatizados em classificações psiquiátricas conduzem aos serviços especializados. E a vida mostra-se cada vez mais constrangida na gestão estratégica do controle e organização estatal.

Engatados a modos de viver dicotomizantes, os movimentos de desterritorialização são continuamente reterritorializados em novas encampações de adoecimento "diante dos atos mais simples de sobrevivência e convivência" (Santos, 2010, p. 1). O "Estado de natureza" de uma população desestabilizada pela ansiedade de classes populares em relação ao futuro, que Santos (2010) relacionava a uma população do final do século passado, hoje, vemos que 
neste domínio, a situação se amplia para outras populações. Movimentos desterritorializantes não significam por si, emancipação, inovação, novas potências de viver. Ficarmos atentos aos movimentos da vida. É inerente à vida. Mas isto produz o quê? A questão é: quais linhas, trajetos e devires- emancipatórios neste emaranhado de forças que constituem os grupos humanos organizacionais são capazes de alterar este estado de coisas? Há um risco de promover a democracia "até não ser necessário nem conveniente sacrificá-la para promover o capitalismo, e com isto, promover uma forma de "fascismo pluralista”, que não é um regime político, trata-se de um regime "social e civilizacional" (Santos, 2010, p. 1).

“A questão que eu ponho não é dos códigos, mas a dos eventos: a lei de existência dos enunciados, o que os tornou possíveis-eles e nenhum outro no lugar deles; as condições de emergência singular deles; a correlação deles com outros eventos..." (Foucault, 1968, p. 681). Pela genealogia, pode-se expor a viabilidade da unificação dos discursos em grandes unidades, tal como "a psiquiatria", "a psicologia". E assim, fazer aparecer seu regime de verdades, que inclui seleção e convencimento para homogeneizar concepções. Entre outras consequências,

pode-se consolidar o fascismo da insegurança:

\begin{abstract}
a manipulação discricionária da insegurança de pessoas e grupos sociais vulnerabilizados por precariedade de trabalho, doenças ou outros problemas, produzindo-lhes elevada ansiedade quanto ao presente e ao futuro, de modo a baixar o horizonte de expectativas e criar a disponibilidade para suportar grandes encargos, com redução mínima de riscos e da insegurança (Santos, 2010, p.2).
\end{abstract}

E com isto a possibilidade de, sob a forma de acolhimento, aproveitar-se da "intimidade das pessoas, sua ansiedade quanto ao presente e ao futuro" e sua vulnerabilidade social, tão naturalizada e ininterruptamente recolocada e disfarçada dentro do estado anormal, hereditário, incurável e subjetivo. E para isto, consolidar o "fascismo da insegurança" (Santos, 2010, p.2).

Estamos dispostos a abrir mão das dicotomias entre saúde e doença? Estamos dispostos a abrir a psicologia para as "Políticas do viver"? (Conde, 2012). Tentar rupturas das dicotomias que constituem razão e desrazão e todo o maquinismo produzido e produtor de novas realidades a respeito do estranho, da diferença? E mais, suportamos questionar nossos especialismos e trazer a psicologia 
para abertura de novos mundos, desconectar discursos sobrecodificantes, atos e significações redutores da vida à institucionalização psiquiátrica?

\section{Notas}

1 Ils ne mouraient pas tous mais tous étaient frappés -Nem todos morriam, mas todos eram afetados", Filme dirigido por Marc-Antoine Roudil (2010), disponibilizado em: $<w w w$. cinefrance.com.br $>$

\section{Referências}

Agamben, G. (2010). Homo sacer: o poder soberano e a vida nua. Belo Horizonte: Ed. Ufmg.

Brasil. (2005). Ministério da Saúde. Secretaria de Atenção à Saúde. Dape. Coordenação Geral de Saúde Mental. Reforma psiquiátrica e política de saúde mental no Brasil. Documento apresentado à conferencia de reforma dos serviços de saúde mental: 15 anos depois de Caracas. Opas. Brasília, DF, nov. 2005. Disponível em: $<$ www.saude.gov.br >acesso em: 22 dez. 2011.
Ceccin, R. \& Feuerwerker. (2004). O quadrilátero da formação para a área da saúde: ensino, gestão, atenção e controle social. Physis: Rev. Saúde Coletiva, Rio de Janeiro, 14(1), 41- 65.

Conde, H. (2012). Temas em debate: ética, sujeito de direitos e instituições. In Participação em mesa-redonda Programa de Pós-Gradução em Psicologia Social e Institucional UFRGS, Porto Alegre (24 ago. 2012).

Deleuze, G, \& Guattari, F. (1992). O que é filosofia? Rio de Janeiro: Ed. 43.

Depression and the global economic crisis: is there hope? The lancet. Uk, v. 380, p. 1203, october 6, 2012. Disponível em <

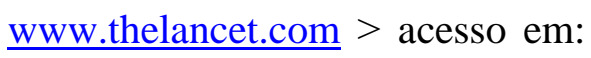
06 out.2012.

Foucault, M. (2006). Aula de 16 de janeiro de 1974. In M. Foucault. O poder psiquiátrico: collège de france, 1973-1974. (pp. 255-284). São Paulo: Martins Fontes.

Foucault, M. (2001). Aula de 19 de março de 1975. In M. Foucault. Os anormais. (pp. 371-409). São Paulo: Martins Fontes.

Foucault, M. (1999). Prefácio (1961). In Ditos e escritos. Problematização do sujeito: psicologia, psiquiatria 
e psicanálise. (pp. 140-148). Rio de Janeiro: Forense Universitária.

Foucault, M. (2004). Arqueologia do saber. São Paulo: Forense universitária.

Foucault, M. (1994). Table ronde du 20 mai 1978. In: Dits et écrits.19541988. Paris: Gallimard, v.4.

Foucault, M. (1994). Entrétien avec Michel Foucault. In Dits et écrits. 19541988. (pp. 140-160). Paris: Gallimard.

Foucault, M. Heterotopias. Disponível em: $<$ http://foucault.info/documents/h eterotopia/foucault.heterotopia.en. html > acesso em: 10 jul. 2012.

Foucault, M. (2005). Microfísica do poder. Rio de Janeiro: Graal.

Foucault, M. (1994). Réponse à une question (1968). In M. Foucault. Dits et écrits. 1954-1988. (v.1). Paris: Gallimard.

Foucault, M. (1994). La pensée du dehors (1966) In M. Foucault. Dits et écrits. 1954-1988. (v.1). Paris: Gallimard.

Foucault, M. (1994). Sur les façons d'écrire l'histoire (1967) In M. Foucault. Dits et écrits. 19541988. (v.1). Paris: Gallimard.

Foucault, M. (2010). Aula de 17 de março de 1976. In M. Foucault. Em defesa da sociedade. São Paulo: Martins Fontes.

Foucault, M. (1994). Des espaces outres (1967) In M. Foucault. Dits et écrits. 1954-1988. Paris: Gallimard.

Informativo eletrônico do Ministério da Previdência Social. Cai número de acidentes de trabalho $e$ aumenta afastamentos por transtornos mentais. Ministério da Previdência e Saúde, Brasília, 16 a 29 de fevereiro de $2012-n^{\circ} 59$. Disponível em: < http://www.mpas.gov.br/arquivos/ office/4_120326-105114-231.pdf >acesso em: 22 out. 2012.

Lobosque, M. (2009). (Org.). Seminário universidade $e$ reforma psiquiátrica: interrogando a distancia. (Cad. Saúde Mental, v.2). Belo Horizonte: Esp-MG.

Pasche, D., \& Passos, E. (2010). Cadernos Temáticos PNH: formação em humanização. Ministério da Saúde. Secretaria de Atenção à Saúde. Política Nacional de Humanização. Formação e intervenção. Brasília, DF, v. 1. Disponível em: $<\mathrm{http}: / /$ bvsms.saude.gov.br/bvs/pu blicacoes/cadernos_humanizasus. pdf $>$ acesso em:14 dez. 2012. 
Santos, B. Os fascismos sociais.

Disponível

em

$<\underline{\text { http://norbertobobbio.com }>}$

acesso em: 15 dez. 2012.

Tania Mara Galli Fonseca: Professora

titular do Instituto de Psicologia da

UFRGS, professora dos programas de pós-

graduação em Psicologia Social e

Institucional e de Informática

Educativa/UFRGS

Email: tfonseca@via-rs.net

Regina Longaray Jaeger: Doutoranda do

Programa de pós-gradução em Psicologia

Social e Institucional da UFRGS. Bolsista

Capes.

Email: regina.longaray@ufrgs.br 